Paidéia, 2004, 14 (28), 197 -209

\title{
GÊNERO, GERAÇÕES E SUBJETIVIDADES NA GRANDE FLORIANÓPOLIS ${ }^{1}$
}

\author{
Mara Coelho de Souza Lago² \\ Carla Michele Serafim \\ Mariana Grasel de Figueiredo \\ Universidade Federal de Santa Catarina
}

\begin{abstract}
Resumo: Esta pesquisa investigou a construção de subjetividades e das dinâmicas de relações geracionais e de gênero, na mudança de espaços e modos de vida de famílias egressas do campo para o meio urbano, na Região Metropolitana de Florianópolis. Foi realizada análise qualitativa de material obtido através de método etnográfico, constando de 16 entrevistas livres, gravadas com sujeitos de diferentes gerações e ambos os gêneros, pertencentes a famílias habitantes dos municípios de Biguaçú e Antônio Carlos. Foram também aplicados 106 questionários com perguntas abertas e fechadas em jovens estudantes dos dois municípios. Foi possível concluir que os sujeitos investigados vivenciam as experiências de urbanização de seus espaços e modos de vida, cada um com suas singularidades, integrando-se a novas atividades nas cidades, ampliando possibilidades e aderindo a outros valores, aproveitando as informações de múltiplos veículos e aprendendo novas tecnologias, ressignificando assim suas estratégias de sobrevivência, suas relações e a si próprios.
\end{abstract}

Palavras-chave: gênero; gerações; modos de vida; urbanização.

\section{GENDER, GENERATIONS AND SUBJECTIVITIES IN THE GREAT FLORIANÓPOLIS}

Abstract: This research investigated the construction of subjectivities and the dynamic of generation relations and gender, in the change of spaces and ways of life of families egresses from the field and agricultural activities to the urban space, in the Region Metropolitan of Florianópolis. Qualitative analysis of material gotten through ethnographical method was carried, consisting in 16 recorded interviews with subjects of different generations and both the genders, pertaining to the families of inhabitants of Biguaçú and Antonio Carlos cities. Also 106 questionnaires with open and closed questions in young students of the both cities had been applied. It was possible to conclude that the subjects live the experiences of urbanization of the spaces and ways of life, each one its way, extending possibilities and adhering to other values, using to advantage the information of multiple vehicles and learning new technologies, thus re-meaning their strategies of survival, social relations and themselves.

Key-words: gender; generations; ways of life; urbanization.

O fenômeno da urbanização, uma das maiores revoluções mundiais das últimas décadas, tem sido particularmente evidente e complexo em alguns países do terceiro mundo, com suas megalópolis. No Brasil, São Paulo é o exemplo mais expressivo. O êxodo do homem do campo tem significado o cresci-

\footnotetext{
${ }^{1}$ Artigo recebido para publicação em 28/05/2003; aceito em 05/01/ 2004.

${ }^{2}$ Endereço para correspondência: Mara Coelho de Souza Lago, Rua Armínio Tavares, 111, Apto. 62, Florianópolis, SC, Cep 88015-250, Email: mlago@cfh.ufsc.br
}

mento exacerbado das periferias urbanas, também de cidades de médio porte.

Santa Catarina é um estado que se caracterizou, em geral, pela agricultura familiar e diversificada, nos moldes da pequena propriedade. O êxodo rural que atinge o estado e alcança também os vizinhos Paraná e Rio Grande do Sul, tem contribuído para o crescimento acelerado de cidades catarinenses com expressiva atividade industrial, como Joinville, ao norte, e Criciúma, ao sul.

Florianópolis, capital do Estado de Santa 


\section{Mara Coelho de Souza Lago}

Catarina, na região sul do Brasil, está localizada na Ilha de Santa Catarina, estendendo-se pelo continente fronteiro, em cuja continuidade emenda, ao sul, com o município de São José e, ao norte, com São José e Biguaçú, que por sua vez, expandem-se em direção aos municípios fronteiros, constituindo o que geógrafos e urbanistas designam de área de conurbação.

Nas periferias da chamada Grande Florianópolis, onde se concentram contingentes da população egressa do campo em várias regiões do estado, há uma mistura de origens étnicas, provindas de zonas diversas de sua colonização ${ }^{3}$. As populações dos municípios conurbados interagem com grande mobilidade, já que os habitantes originais e os migrantes, morando em um deles, trabalham, estudam, buscam recursos de saúde, lazer, serviços, etc., nos municípios vizinhos. As atividades industriais não se constituem como setor importante da economia dos municípios que compõem a Grande Florianópolis, área de conurbação, o que agrava o problema da absorção de mão-de-obra.

São bastante desenvolvidos os setores de serviço, no comércio, finanças, administração pública, além dos empregos que envolvem mão-de-obra não qualificada e da expressão da economia informal. Na atividade industrial, o grande empregador é o setor da construção civil, com alguma expressividade para indústrias de pequeno porte voltadas para o consumo interno, como móveis, produtos alimentares, vestimentas...

O incremento crescente da atividade turística e a implantação de campus das universidades privadas que compõe o sistema fundacional de estudo superior do estado de Santa Catarina, em Biguaçú, Palhoça e São José, tem contribuído para fortalecer os movimentos migratórios para e entre os municípios da Grande Florianópolis.

Esta linha de pesquisa reflete sobre a trajetória de sujeitos no processo de urbanização de seus espaços de vida e formas de trabalho. Tendo por ob-

\footnotetext{
${ }^{3}$ Nos arredores de Florianópolis habitam, em geral, os descendentes de açorianos que colonizaram o litoral do estado e a Ilha de Santa Catarina. Os alemães, descendentes dos criadores da antiga colônia de São Pedro, concentram-se mais em Santo Amaro e Antônio Carlos (Alto Biguaçú). Para Biguaçú, São José e bairros continentais de Florianópolis, vêm, de Lages e arredores do planalto serrano, de Chapecó e outras cidades do oeste catarinense, os caboclos e os descendentes de italianos que, oriundos do Rio Grande do Sul, povoaram o interior do estado.
}

jetivo o estudo da dinâmica das relações geracionais e de gênero, relações familiares portanto, em função das mudanças decorrentes da migração do campo para a cidade e das atividades na agricultura para 0 trabalho nos espaços urbanos. Desenvolveu, inicialmente, seus estudos na Ilha de Santa Catarina, centrados na população dos descendentes de açorianos que habitavam suas localidades litorâneas, vivendo da pesca artesanal e do trabalho na lavoura ${ }^{4}$.

O crescimento de Florianópolis, a partir das décadas de 60, 70, em função de inúmeros fatores (Lago, 1996; Lago, 1996) e do incremento das atividades turísticas, expandiu a cidade sobre os espaços litorâneos, inviabilizando, muitas vezes, as formas tradicionais de trabalho e provocando profundas alterações nos modos de vida de seus habitantes originais.

Os estudos de gênero, a partir da utilização desta categoria, que aponta para o caráter relacional da construção de feminilidades e masculinidades, têm enfatizado tradicionalmente a importância de se perceber, nas pesquisas, que os sujeitos se constituem em posições atravessadas por diferenças de classe, de etnia, gênero, gerações, origem rural ou urbana, etc.

Esta linha de pesquisa tem se dedicado, assim, a estas questões. A partir dos estudos com sujeitos de origem açoriana, buscou aprofundar reflexões sobre as tradições culturais étnicas que marcam modos de vida, voltando-se para as populações de descendentes de alemães e outras etnias, que habitam a Região Metropolitana de Florianópolis.

A escolha dos municípios de Biguaçú e Antônio Carlos, (além da origem alemã da maioria dos habitantes deste último e do fato de ter como atividade econômica mais expressiva, a produção agrícola), deveu-se à orientação buscada na pesquisa que Marcon (2000) desenvolveu na UFSC, sobre a metropolização de Florianópolis, diferenciando estágios nesse processo, em que alguns municípios se apresentavam no que chamou de conurbação consolidada (Florianópolis, Biguaçú, São José e Palhoça); outros, no que designou como em processo de conurbação (Santo Amaro e Águas Mornas); o município de Antônio Carlos, com tendência à conurbação; outros, num estágio mais inicial do processo, que caracterizou como de forte integração

\footnotetext{
${ }^{4}$ Os homens praticando sazonalmente a pesca embarcada no litoral do Rio Grande do Sul.
} 
(Governador Celso Ramos e São Pedro de Alcântara) $)^{5}$.

Partindo de Florianópolis, a linha de pesquisa estendeu seu campo, nesse momento, para um dos municípios de conurbação consolidada, Biguaçú, com processo menos avançado de crescimento urbano, em relação a São José e Palhoça, e Antônio Carlos, em pleno estágio do que Marcon designou como processo de conurbação. O município de Antônio Carlos faz divisa com Biguaçú, para onde migram, num primeiro momento, muitos dos habitantes de Antônio Carlos egressos do trabalho na terra. Enquanto para Biguaçú afluem migrantes de descendências étnicas variáveis, os habitantes de Antônio Carlos são, em sua maioria, descendentes de alemães. Este município tem como principal atividade econômica, o cultivo de produtos hortifrutigrangeiros para o abastecimento da Região Metropolitana.

\section{Reflexões Teóricas}

Os trabalhos produzidos nesta linha de pesquisa são devedores de toda a tradição de estudos rurais e dos estudos sobre campesinato, com enfoque nas trajetórias de sujeitos e famílias do meio rural para as cidades. Tem-se achado proveitoso, atualmente, recorrer a conceitos desenvolvidos por Louis Dumont (1985; 1992), apropriados e repensados, no Brasil, por autores como Luiz Fernando Duarte (1986), Roberto Da Matta (1978), Gilberto Velho (1983, 1987), Sérvulo Figueira $(1985,1987)$ e, nos estudos de gênero, por Maria Luiza Heilborn (1992) e Tânia Salém (1989), entre outros.

As leituras que orientam as reflexões e interpretações produzidas por esta linha de pesquisa, teorizam a construção de subjetividades sendo significadas e significando os códigos simbólicos com que as culturas constituem sujeitos. ${ }^{6}$ Nestas perspectivas, é importante considerar os grupos sociais de contato inicial e direto, que traduzem para a criança em desenvolvimento, os significantes dos códigos culturais através dos quais constroem subjetividades. Fator que justifica o interesse da investigação voltar-

\footnotetext{
${ }^{5}$ Conferir mapa elaborado pela autora (Marcon, 2000, p. 54). ${ }^{6}$ Sujeitos do discurso. Discurso que, conforme ressalta Lacan, faz laço social.
}

se para as relações familiares, de gênero e gerações.

Na comparação entre modos de vida rurais, em regime de pequena propriedade trabalhada por mão-de-obra familiar, e modos de vida urbanos, mesmo em cidades de médio porte, uma das diferenças que se pode ressaltar é aquela concernente aos tipos de organizações de famílias. No meio rural, em geral, constituídas segundo um modelo tradicional, mais próximo da família patriarcal, fundada em princípios de hierarquia, com funções, direitos e deveres claramente definidos e diferenciados, destacando a figura do pai como detentora principal da autoridade, das decisões e responsabilidades na provisão da subsistência familiar. Nas cidades, famílias nucleares, perseguindo ideais igualitários, com ênfase nos valores caracterizados por Dumont (1985) como individualistas ${ }^{7}$.

Dumont (1985), estudando a Índia, caracteriza-a como uma sociedade hierárquica, em contraposição às sociedades ocidentais "modernas", que caracteriza como individualistas. A primeira, marcada pelo holismo, "ideologia que valoriza a totalidade social e negligencia ou subordina o indivíduo", as sociedades ocidentais marcadas pelo individualismo "ideologia que valoriza o indivíduo ... e negligencia ou subordina a totalidade social” (p. 259). Enquanto a primeira privilegia a consideração das diferenças na composição do todo social, as sociedades modernas se pautam por ideais igualitários. Conceitualizando hierarquia, Dumont ressalta "a distinguir do poder ou comando; ordem resultante do emprego do valor, a relação hierárquica elementar (ou oposição hierárquica) é a existente entre um todo (ou conjunto) e um elemento deste todo" (p. 259).

Em outra obra, o autor explica:

Acredito que a hierarquia não seja essencialmente uma cadeia de ordens superpostas, ou mesmo de seres de dignidade decrescente, nem uma árvore taxonômica, mas uma rela-

\footnotetext{
${ }^{7}$ Diante da variedade de arranjos familiares que a história e as dinâmicas culturais possibilitam, a caracterização é generalizadora, por não estar considerando outras diferenças, como classes sociais, níveis de renda, escolaridade, acesso à informação, etc, tanto no meio rural como na cidade, onde as diversidades se tornam ainda mais evidentes. O trabalho proposto pretende buscar, partindo desses modelos teóricos, a heterogeneidade na singularidade de experiências familiares e de sujeitos, nos processos de mudança para o meio urbano.
} 
ção a qual se pode chamar de englobamento do contrário (...) o elemento faz parte do conjunto, é-lhe neste sentido consubstancial ou idêntico, e ao mesmo tempo dele se distingue e se opõe a ele. (Dumont, 1992, p. 370)

Dumont define a oposição hierárquica como relação englobante - englobado, relação entre o conjunto e o elemento.

A análise das relações hierárquicas através dos níveis propostos por Dumont (1992) (no primeiro nível ocorrendo identidade entre os elementos, no segundo, revelando-se a diferença de complementaridade ou de oposição entre os componentes), parece fecunda para possibilitar a compreensão, tanto da justaposição de modelos de relações e organizações sociais contraditórios, como das transformações sociais, quando o elemento englobante passa a ser englobado, e vice-versa.

É neste sentido que o autor tem sido apropriado, especialmente por Duarte (1986) e Heilborn (1992) e pode nos facilitar a análise de modelos hierárquicos e igualitários de família, coexistindo (nos níveis inter e intrapsíquicos) na contradição entre os ideários simbólicos que colocam o valor no coletivo e aqueles que elegem o indivíduo como valor primeiro.

Na análise do material obtido no trabalho empírico de pesquisa, é assim importante poder recorrer a uma teoria que permita refletir sobre as situações que, na condição pós - moderna (Harvey, 1989; Lyotard, 1998) e na contramão dos movimentos de globalização, fazem eclodir com força redobrada as lutas identitárias, afirmando as pequenas e grandes diferenças entre os grupos sociais (étnicos, religiosos, etc.) que competem por espaços, oportunidades e acesso aos bens materiais e culturais. Um mundo cada vez mais marcado pela fragmentação, a nuclearização, a exacerbação do indivíduo como valor, velando a percepção das diferenças, na homogeneização promovida pela ideologia do igualitarismo.

Acredita-se que a oposição entre ideários de organização familiar que, com o fenômeno da globalização das comunicações pela mídia antecede a migração das populações do campo para as cidades, deva se tornar sensivelmente explícita no espa- ço urbano, exacerbando a vivência de conflitos que são próprios das relações familiares.

Os estudos sobre mulheres, que eclodiram na esteira dos últimos movimentos feministas, acompanharam/provocaram reformulações de categorias de análise e a subversão de paradigmas teóricos. Foi neste contexto que se introduziu a categoria de gênero, que permitiu a reflexão sobre diferenças que ficavam subsumidas nas análises das ciências sociais.

Os estudos de gênero são, fundamentalmente, interdisciplinares, devendo muito de seu desenvolvimento à antropologia, à história, à teoria literária. A psicologia tem estado a reboque destas disciplinas, com relação a eles. A psicanálise, no entanto, tem sido interlocutora privilegiada das teorias feministas de outras áreas, em diálogos muitas vezes carregados de tensões. Pelo fato de Freud ${ }^{8}$ ter construído um paradigma que teoriza a constituição psíquica de sujeito (inconsciente) nas vicissitudes pulsionais das identificações diferenciadoras, de identidades, de masculinidades, de feminilidades, este diálogo, acredita-se, é importante para refletir sobre as questões de gênero que os trabalhos de campo trazem, invariavelmente, à análise dos pesquisadores.

Nos trabalhos que procuraram analisar especificamente questões de gênero, já realizados por esta linha de pesquisa, os relatos dos informantes ressaltaram, em geral, como foco freqüente de conflitos familiares nos processos de mudanças dos seus modos de vida, as relações mais difíceis com as figuras paternas $^{9}$.

Pensando que a superposição dos modelos tradicionais (hierárquicos) e individualistas (igualitários) de famílias possa estar sendo vivenciada, nos processos de urbanização, com particular dificuldade pelos homens, este estudo desenvolveu uma reflexão também atenta às questões da masculinidade.

Nos espaços urbanizados em que as ofertas de trabalho se concentram principalmente no setor de serviços, têm sido cada vez mais freqüentes maio-

\footnotetext{
${ }^{8}$ Em toda a sua obra, cuja produção se inicia no final do século XIX e se estende pelas três primeiras décadas do século XX.

${ }^{9}$ Estudos das trajetórias de mulheres (Lago, Sousa \& Vieira, 1995) e de adolescentes de ambos os gêneros (Lago, Santos \& Silva, 1996) na urbanização das localidades da Ilha de Santa Catarina, ou na migração de informantes para a cidade de Florianópolis.
} 
res oportunidades para absorção da mão-de-obra feminina. Nestes tempos de globalização neoliberal e de recessão econômica do país, a questão do desemprego dos pais de família tem-se tornado particularmente dramática. Além do aumento do número de famílias constituídas apenas por mulher e filhos, muitas organizações familiares que incluem a presença do pai estão dependendo, cada vez mais, do trabalho feminino, nos largos períodos em que os homens permanecem em casa, desempregados ${ }^{10}$.

Muitos autores têm ressaltado a importância do trabalho como um dos marcos definidores das identidades masculinas, principalmente entre as camadas populares (Romanelli, 1993). A ligação entre ser homem e ser trabalhador, foi ressaltada nos relatos dos informantes de diferentes gerações, nas etnografias realizadas. A ideologia do trabalho como definidora da identidade germânica tem sido analisada, no estado de Santa Catarina, especialmente por Giralda Seyferth (1974). Psicólogos da UFSC estudaram também, nas representações sociais de descendentes de alemães e portugueses do Vale do Itajaí, o peso da categoria trabalhador como diferenciador, inclusive, das duas etnias (Paquete, 1994; Schulze, 1996).

\section{Método}

A pesquisa realizou análise qualitativa de material obtido através de método etnográfico. O trabalho de campo constou de entrevistas livres gravadas com sujeitos de diferentes gerações e ambos os gêneros, pertencentes a algumas famílias de habitantes dos municípios pesquisados. Foram também aplicados questionários com perguntas abertas e fechadas em adolescentes dos dois municípios, utilizados como subsídio para a contextualização das populações estudadas, além de propiciarem a análise de temas específicos sobre família e sobre adolescência.

A pesquisa abrangeu sujeitos de ambos os sexos, entre eles criança, adolescentes, adultos e velhos, num intervalo de idade entre 8 e 62 anos, sujeitos estes provenientes de diferentes locais dos municípios de Biguaçú e Antônio Carlos, na Região Me-

\footnotetext{
${ }^{10}$ Conferir o estudo de Maria Juracy T. Siqueira (2000), sobre a inversão dos papéis tradicionais masculinos e femininos em uma família de camadas populares de Florianópolis, frente a esta questão.
}

tropolitana de Florianópolis. Os sujeitos pesquisados possuíam diferentes graus de escolaridade e variados tipos de inserção no mercado de trabalho, tendo em comum o fato de pertencerem a famílias que trabalharam (ou trabalham) na agricultura.

Em Antônio Carlos foram realizadas dez entrevistas num total de quatro homens e seis mulheres com idades entre 25 e 62 anos. Foram aplicados 67 questionários entre adolescentes de duas escolas desse município, respondidos por um total de 32 moças e 35 rapazes. As idades desses jovens variaram entre 12 e 18 anos.

Em Biguaçú foram realizadas seis entrevistas, com um homem, duas mulheres, duas jovens e uma menina. As pessoas entrevistadas pertencem a duas famílias que habitam no município. Uma delas, mudou-se há poucos anos para Biguaçú, vinda de São Miguel do Oeste onde desenvolvia originalmente atividades agrícolas. A outra família pesquisada morava há 22 anos em Biguaçú, sendo o casal de origem alemã oriundo do município de Antônio Carlos, onde ambos trabalhavam na lavoura.

Neste município foram aplicados ainda 24 questionários em adolescentes que estudam em escolas públicas e 15 entre adolescentes que freqüentam um grupo de jovens da Igreja do bairro onde moram as famílias entrevistadas. Em Biguaçú, os questionários foram respondidos por 33 moças e apenas 6 rapazes, sendo que as idades dos sujeitos que participaram da pesquisa neste município estavam numa faixa entre 8 e 57 anos.

\section{Resultados}

Pelas respostas aos questionários, pode-se perceber que a maioria dos pais dos jovens de Antônio Carlos tinham trabalhado na lavoura anteriormente, enquanto menos da metade deles continuava com este tipo de atividade na época em que se realizou a pesquisa.

As entrevistas corroboraram e coloriram estas informações com as questões subjetivas dos informantes, rememorando suas histórias de vida. Todos os sujeitos entrevistados em Antônio Carlos tinham trabalhado na lavoura quando crianças, os quatro homens e as seis mulheres. No entanto, apenas um dos homens continuava com o trabalho agrícola, 


\section{Mara Coelho de Souza Lago}

em terras que arrendava, perto de sua residência, já que o lote onde mora não é extenso o suficiente. Este sujeito é casado com uma das irmãs entrevistadas, que trabalhou também como doméstica em Florianópolis e no próprio município. Quando solteira foi funcionária de uma indústria de móveis em Antônio Carlos por 12 anos, época em que se casaram, após longo namoro e noivado, possuindo um casal de filhos.

Este entrevistado falou longamente da instabilidade de sua situação econômica atual, atribuindo-a, com certa mágoa, ao fato dos pais não lhe terem proporcionado oportunidade de continuar os estudos, como fizeram com dois de seus irmãos mais novos que puderam cursar as últimas séries do $1^{\circ}$ grau e o ensino de $2^{\circ}$ grau. Procurava complementar a renda trabalhando com o cunhado pedreiro em construções no próprio município e cuidava do filho pequeno quando a mulher saía para fazer serviço de faxineira em Florianópolis. Ambos enfatizaram, em suas falas, a ajuda mútua nos trabalhos que desempenhavam dentro ou fora de casa, sem se desligarem, no entanto, de uma divisão mais tradicional das atribuições femininas e masculinas. Possuíam uma boa casa de alvenaria nos moldes das residências urbanas, com suíte para o casal, os quartos e o banheiro das crianças, sala de visitas, sala de televisão, varanda, churrasqueira, guardando em comum com as residências antigas de estilo germânico, uma cozinha espaçosa e bem equipada, com grande mesa rodeada por cadeiras ao centro. A casa fora construída com o dinheiro da indenização que a esposa recebera da indústria da qual fora despedida depois da licença de gestação do segundo filho. Na ocasião, puderam comprar um carro de segunda mão e, na época da pesquisa, esforçavam-se para manter os bens que adquiriram. Ela se sentia desconfortável com o fato de não ter conseguido outro emprego, compatível com o nível de escolaridade de $2^{\circ}$ grau que possuía, tendo que aceitar trabalho de diarista, quando o marido podia ficar com o filho menor. A menina já estava na escola e o grande projeto do casal para o futuro referia-se a proporcionar estudo para os filhos, de forma que tivessem uma vida menos trabalhosa que as deles e de seus pais, que tinham sido agricultores a vida toda.

O primeiro homem entrevistado no município, casado, com quatro filhos, trabalhava numa pla- taforma da Petrobrás no Rio de Janeiro, onde passava parte do mês. Só possuem quatro filhos, o que acham muito, porque os três primeiros foram homens e a esposa queria uma menina. Sendo o mais velho de oito filhos, de pais que trabalhavam na lavoura, contou da dificuldade que tivera para continuar os estudos quando foi implantado o $2^{\circ}$ grau de ensino no município, já que o pai achava que ele deveria continuar envolvido apenas com o trabalho familiar no cultivo da terra. Sua esposa, que não nascera em Antônio Carlos e possuía também o $2^{\circ}$ grau de escolaridade, fora funcionária de empresa em Florianópolis, mas deixara de trabalhar para cuidar dos filhos. Ele faz investimentos comprando terras no município, aumentando sua propriedade a partir do lote que ganhou do pai quando casou (como também aconteceu com as irmãs que continuaram morando no município depois de casadas). Seu projeto e da esposa refere-se principalmente em investir na educação dos filhos, que querem ver cursando uma universidade. Além das terras, possui algumas cabeças de gado e, se não se dedica a plantar mais do que uma horta para o consumo, é porque suas atividades profissionais não lhe permitem e os filhos agora só estudam.

Os outros homens entrevistados em Antônio Carlos realizaram curso superior e trabalhavam, um como secretário do governo municipal responsável pela área social, e o outro como professor da escola pública de $1^{\circ}$ e $2^{\circ}$ grau.

O primeiro morou em Florianópolis depois que casou, local em que nasceram suas quatro filhas, voltando para Antônio Carlos para participar da gestão de prefeito do seu partido, com uma proposta de investir no desenvolvimento do setor educacional no município. Conforme relatou, a prefeitura integrou escolas isoladas, oferecendo transporte para as crianças das regiões mais afastadas, implantou ensino pré-primário em estabelecimento no centro urbano com condução para as crianças e negociou com a fábrica da Coca-Cola que se instalou no município, a implantação de curso supletivo, que beneficiava também os funcionários dessa indústria. Além de manter as crianças e jovens na escola, a prefeitura oferece passes escolares para aqueles que realizam o $2^{\circ}$ grau na Escola Técnica, em São José e Florianópolis, assim como para os jovens que cursam o ensino supe- 
rior em Biguaçú e Florianópolis. O município não possui hospital, só ambulatório de saúde e ambulância para o transporte de doentes, que buscam tratamento em São José e Florianópolis. Este senhor ressaltou os índices de qualidade de vida de Antônio Carlos, onde os trabalhadores ainda podem se manter no trabalho agrícola, comercializando a produção na Região Metropolitana. Falou de dificuldades na concorrência com produtores agrícolas de outros locais que se especializam no cultivo sem agrotóxicos, ainda não desenvolvido de forma significativa no município, e falou também da preocupação com problemas de drogas, que já começavam a aparecer entre jovens.

O professor entrevistado em Antônio Carlos, deteve-se especialmente em comparar os modos de vida antigos, de sua família de origem, com as formas atuais como as crianças e jovens são educados. Falou de relacionamentos, ressaltando os conflitos geracionais, contando que as pessoas estudavam até a $4^{\mathrm{a}}$ série e depois paravam para auxiliarem os pais na roça. As crianças pequenas ajudavam nos serviços da casa, da roça, vindo daí a necessidade dos casais terem muitos filhos "os filhos eram uma mão de obra, quer dizer, não era gratuito, mas também não tinham que pagar". As famílias tinham de 10 a 12 filhos, seis no mínimo, mas as formas de educação eram rígidas. Conforme o seu relato, era o jeito que os pais tinham de controlar a situação "e era até um tipo de escravidão que hoje muito adultos têm lembranças ruins daquele tempo". Não existia diálogo com o pai e a mãe, as crianças tinham que obedecer. "Hoje não, os filhos querem mandar no pai (...) Naquele tempo muitos pais já até escolhiam a forma como o filho devia namorar, ou que devia casar (...) todos já procuravam logo namorar com as pessoas que a família conhecia (...) e com isso ter o aval deles...”, conforme ele ressalta. O mesmo informante relata também que naquele tempo as pessoas eram felizes com o pouco que tinham, e que hoje em dia, tudo mudou “....as pessoas buscam cada vez mais atrativos para serem felizes e parece que existem poucas soluções. Mas naquele tempo as famílias viviam unidas (...) tentavam ajudar umas às outras, conversar mais entre as famílias, e assim espantar a solidão.” Ele acha que hoje, nas cidades, as pessoas vivem tensas, preocupadas em possuir mais do que os outros.
Este informante havia cursado o $2^{\circ}$ grau no município e após ter-se casado foi trabalhar em Florianópolis, onde fez curso superior, voltando como professor da escola pública de Antônio Carlos. Tanto ele como o secretário municipal, que já tem três filhas cursando universidade, em Florianópolis e Biguaçú, pretendem ver os filhos realizando cursos superiores.

A senhora entrevistada, que possui magistério, é diretora da creche municipal e foi morar em Florianópolis depois de casada, local onde nasceram suas quatro filhas. Tinha muita vontade de voltar para o município de origem, onde deseja permanecer, ao contrário das filhas e mesmo do marido, de gostos mais urbanos que ela. Falou da importância do convívio com a família extensa de origem e da vida mais comunitária que levam no local, mesmo no desempenho de trabalhos "urbanos". A filha mais moça encarrega-se da casa quando ela sai para trabalhar. Conta que o marido dividia com ela as tarefas domésticas e o cuidado das crianças, quando moravam na cidade, o que agora não faz mais, talvez porque as filhas já cresceram e ela pode contar com a ajuda das parentes. Ela mantém uma horta e planta flores, enaltecendo este tipo de trabalho como prazeroso, oportunizando o continuar a mexer com a terra.

A senhora de 62 anos entrevistada em Antônio Carlos, é viúva e continua na casa em que morou com o marido, construída em 1899 pelos avós deste, da qual tem imenso orgulho e que é realmente uma bela residência de estilo germânico. Esta mulher, que tem filhos casados morando perto dela, assim como em Florianópolis e Blumenau, que possui vários netos, falou detidamente do trabalho feminino na casa e fora dela, acompanhando o marido na roça. Contou do aprendizado de habilidades diversificadas: a culinária, a costura, o bordado, crochê, tricô, que lhe proporcionaram o complemento da renda, já que cozinhava e fazia doces para festas. Atualmente, dá aulas de bordado para um grupo de mulheres de terceira idade na paróquia do município, atividade que a ajuda a enfrentar a solidão da viuvez, após toda uma vida de esforços e prazeres partilhados. Falou de gerações se sucedendo e convivendo, de religião, das festas comunitárias e familiares. Enquanto dava a entrevista, mostrava a casa, as folhagens bem cuidadas, os bordados que fazia para a família e para ven- 


\section{Mara Coelho de Souza Lago}

der, a bonita vista de sua janela para o açude e o campo fronteiro, contornados pelas montanhas, as magníficas rosas que cultivava e a horta de onde tirava os legumes e verduras que consumia. A filha mais moça, casada e mãe de um bebê mora provisoriamente com ela e a casa vive cheia dos netos, noras, filhos, que moram ao redor.

Outra senhora entrevistada em Antônio Carlos vive em casa alugada com os dois filhos moços e o companheiro. Separou-se do marido com quem casou muito cedo e que passou a beber quando teve que sair da propriedade dos pais, que não era suficiente para manter todos os filhos no cultivo da terra. Ela faz o trabalho de diarista em Florianópolis, pegando duas conduções e tendo que levantar muito cedo para chegar ao trabalho na cidade. Em sua casa, já velha mas muito limpa e arrumada, todos trabalham, dividindo as despesas. Apesar da distância que precisa percorrer para trabalhar, essa senhora arrola muitas vantagens em permanecer morando em Antônio Carlos, mesmo sem possuírem terras para o cultivo: a convivência com os parentes, os amigos, a união com os filhos ainda solteiros, a qualidade do ar que respiram, além do custo de vida ser menor.

Das pessoas que continuavam a trabalhar com agricultura, entrevistaram-se duas moças. A mais velha, solteira, de 39 anos, tinha estudado até o nível médio e se empregara numa firma de Biguaçú, onde morou por vários anos. Teve um filho e voltou para a casa dos pais em Antônio Carlos com o menino, onde trabalha na lavoura, substituindo o pai, aposentado, e levando o empreendimento agrícola da família associada a um irmão casado. Seu filho de 11 anos, estuda e ajuda na lavoura onde plantam os produtos que comercializam no Ceasa, que abastece a Região Metropolitana, e em feiras de Florianópolis. Gostava da lavoura e não pretendia voltar para o trabalho urbano. Seu relato enfatizou a importância do relacionamento com a família de origem, muito extensa, abrangendo tios e primos. Costumava freqüentar festas e danceterias em Biguaçú, Florianópolis e São José, tendo uma roda grande de amigos, especialmente em Biguaçú.

A outra moça entrevistada na localidade, com 25 anos, era casada há um ano e trabalhava com o pai, a mãe e um irmão mais moço no cultivo de hortifrutigranjeiros. Já havia trabalhado em casa co- mercial do município e possuía, como a irmã (também entrevistada), uma casa nova, em padrões modernos urbanos, construída pelo marido, pedreiro, em terreno doado pelos pais dela. Precisava ainda construir os muros da residência e o filho que desejavam ter e para o qual já tinham o quarto, estava programado para depois de terminarem a casa. Apesar de gostar do trabalho na lavoura, ela desejava voltar a se empregar no comércio. Se este projeto não desse certo, aceitaria até o trabalho como diarista, desde que fosse em Antônio Carlos.

Dava para perceber o investimento na casa e no trabalho doméstico por parte das famílias, tanto das mais jovens, quanto da mais velha e daquela que não possuía casa própria. Estas mulheres enfatizaram em suas falas, o valor para a família e os empreendimentos conjuntos das esposas "trabalhadeiras".

Em Biguaçú, nas duas famílias pesquisadas, foram entrevistadas duas jovens solteiras, uma menina de oito anos, além das duas mães e de um dos pais.

A menina ofereceu um bonito relato, descrevendo os seus relacionamentos com a família, os projetos dos pais e irmãos mais velhos, sua vida na casa e na escola, suas expectativas, sonhos, frustrações. Não tinha sido escolhida para dançar o pau de fita na festa junina da escola; não pudera ser dama, levando as alianças no casamento da tia porque o vestido para alugar era caro; quando começasse a trabalhar poderia ter dinheiro para ir ao parque do Beto Carrero e para comprar os brinquedos que via anunciados na televisão. Mas estava muito feliz com o fato de ter ganho um sobrinho, filho do irmão mais velho. Cuidava do irmão menor e ajudava o outro, de 16 anos, no serviço da casa, quando a mãe saía para o trabalho de diarista. Circulava muito pelas casas dos tios, tias, avós, que moravam nas vizinhanças, vindos, como eles, do oeste de Santa Catarina. O pai era carinhoso e protetor com ela, que se entendia muito também com a mãe. Mostrou a horta para a entrevistadora, dizendo o nome de cada planta, de cada chá que cultivava. Não gostava das brincadeiras dos meninos, o futebol, muito bruto, mas brincava com os primos/as e colegas da escola. Parecia entender muito bem o que podia ter agora e o que precisava adiar para o futuro remoto, em função dos custos. Gostava de estudar, como o irmão adolescen- 
te que tinha planos para cursar faculdade.

Sua mãe trabalhadora rural em criança e jovem, depois empregada em casa de família, casarase com um viúvo, pai de dois filhos, que ajudara a criar. A família teve um empreendimento agrícola em São Miguel do Oeste, com máquinas e animais e não conseguira sustentá-lo, em função dos juros bancários que assumiam para implementar o cultivo, mudando-se para o perímetro urbano daquele município, num primeiro momento, onde tentaram várias atividades para a sobrevivência. Num segundo momento, migraram para Biguaçú, local onde já tinham vindo morar vários irmãos do marido, em busca de trabalho na Região Metropolitana de Florianópolis. Ali também fizeram algumas tentativas diferenciadas de trabalho, como venda de antenas parabólicas, consertos de aparelhos elétricos, tendo formado na ocasião, uma banda para tocar em festas. Pareciam estar sobrevivendo com esta atividade e já possuíam um ônibus para se deslocar com a banda, composta pelo pai, os filhos e parentes. A esposa, no entanto, precisava continuar com o trabalho de diarista e o dinheiro que ganhava dava para o marido, que tomava todas as decisões econômicas da família. Ela enalteceu o marido pelo fato de ajudá-la no cuidado com os filhos.

As jovens de 17 e 15 anos, entrevistadas na outra família, de pai e mãe descendentes de alemães, que trabalhavam na lavoura em Antônio Carlos e vieram para Biguaçú quando casaram, falaram de seus estudos, do relacionamento com os pais, o irmão, os amigos. Contaram a respeito dos locais que freqüentavam para diversão, dos relacionamentos com os rapazes, da participação no grupo de jovens da igreja do bairro (católica), compararam seu envolvimento e o da geração de seus pais com a religião, falaram de seus projetos para o futuro. Na ocasião, cursavam o $2^{\circ}$ grau e pretendiam, ambas continuar os estudos na universidade. A mais velha já trabalhara como bolsista em escolas, já realizara trabalhos para o censo do IBGE e, além de cuidar da casa desde pequena, quando a mãe se empregara em Florianópolis, não gostava de ficar sem um ganho extra. Era bastante envolvida com os projetos familiares. Relataram que o irmão não precisava realizar tarefas domésticas em casa da mesma forma que elas, por serem mulheres. A mais moça era mais centrada em seus próprios pro- jeto e não gostava de morar em Biguaçú, local que considerava pequeno, sem nada para fazer. Pretendia transferir-se para a escola Técnica Federal, em São José, onde acabaria um curso profissionalizante, como o irmão mais velho, para continuar os estudos.

O pai, senhor de 57 anos, trabalhara na lavoura até casar, com 32 anos. Só dois de seus irmãos puderam permanecer no campo plantando, quando os pais morreram, comprando a parte das terras que os demais receberiam, no sentido de viabilizarem o projeto agrícola. Ele custou muito a se acostumar na cidade, onde empregou-se no setor de construção civil como ajudante de pedreiro, mais tarde responsável pela confecção de caixaria para os fundamentos dos prédios construídos pelas firmas em que trabalhava. A renda era complementada pelo trabalho da esposa em Florianópolis. Achava que os irmãos que viviam da terra, apesar da vida trabalhosa que também levavam, tinham condições econômicas melhores. Pensava bastante na aposentadoria que estava próxima e via vantagem na aposentadoria dos agricultores, que tinham uma garantia de ganho mensal na velhice, diferente da geração de seus pais, que ficavam dependendo dos filhos quando não podiam mais trabalhar. Via muitas facilidades na vida do jovem atualmente, ponderando que em seu tempo de infância e juventude, era vantajoso ser pai, agora as vantagens são dos filhos. “...hoje tá mais fácil ser filho que ser pai”, conforme comenta com seus irmãos mais velhos. Sua residência foi construída por ele sobre dois lotes, um dos quais utiliza para plantar alguns produtos para o gasto, comercializando o excedente. Gosta do serviço da terra e tem saudades do tempo que era agricultor, fazendo "de tudo".

A esposa deste senhor, informante que ajudou as pesquisadoras a formar a rede de entrevistados a partir de parentes, amigos e conhecidos nos dois municípios, contou que trabalhara na roça dos nove aos 20 anos, quando o pai vendeu o terreno para os filhos mais velhos, porque não podia continuar trabalhando e precisava de dinheiro para sustentarse e à mulher, já que não possuía aposentadoria. A entrevistada trabalhou como doméstica em residências particulares em Blumenau e Florianópolis, tendo voltado para Antônio Carlos quando o irmão mais velho perdeu a esposa e precisou que ela viesse cuidar dos sobrinhos. Anos mais tarde, com o novo ca- 


\section{Mara Coelho de Souza Lago}

samento do irmão, ela casou-se também, tendo insistido para o marido abandonar o serviço na lavoura, indo morar em Biguaçú. Após ter trabalhado em pequena indústria neste município, ficou alguns tempo desempregada cuidando dos filhos, tendo retornado ao trabalho como doméstica quando a menina menor estava com seis anos e a outra, de oito, já podia ajudála no trabalho da casa, esquentando inclusive a comida que ela deixava pronta à noite, para o dia seguinte. O menino, dois anos mais velho que a irmã, só fazia as coisas em casa quando as meninas não estavam. Ela tomava dois ônibus para ir trabalhar e não chegava atrasada ou faltava ao emprego, onde cozinhava e cuidava da casa. Orgulhava-se do serviço bem feito e tinha muitas habilidades, como as mulheres de sua família "no sítio". Sua mãe só falava alemão e ela fora aprender português na escola primária que cursou até a 4 a série. Ela contou que os pais eram enérgicos e os irmãos mais velhos também mandavam nos mais novos. Tinha 16 irmãos vivos e era a filha mais nova. Fizera um investimento continuado na educação dos filhos, não contanto sempre com o apoio do marido, que pensava que os jovens podiam começar a trabalhar mais cedo, contribuindo com as despesas familiares, como acontecera na sua e nas outras famílias de sua geração.

A informante é muito religiosa e atuou bastante, junto com o marido, nas atividades da igreja do bairro que mora. Seu dinheiro é controlado por ela que o gasta na casa, para ter mais conforto, e com as necessidades, roupas, estudos dos filhos. Sempre teve preocupação em proporcionar-lhes, além do estudo, cuidados de saúde, serviços odontológicos, etc.

Na época da pesquisa estava lidando com um pouco de dificuldade com o fato do filho que, estando formado em curso profissionalizante do $2^{\circ}$ grau e já trabalhando no local onde prestara estágio curricular, tinha saído de casa para morar com a namorada, mais velha e mãe de três filhos. A família esperava que, com o auxílio do rapaz que progredira no emprego, pudesse tornar realidade a compra de um carro, para o qual o casal economizava há bastante tempo. Estava sentida com a ausência do filho, mas desejava vê-lo feliz e, principalmente, continuando os estudos. A entrevistada é uma figura forte e, mesmo desenvolvendo um trabalho que é a continuidade das atividades do lar, conquistou bastante auto- nomia, embora não se volte para projetos individuais, priorizando as questões familiares.

Com relação aos jovens que responderam aos questionários em Biguaçú, pode-se perceber que a maioria das famílias é migrante do trabalho rural e que a geração dos pais desenvolve atividades especialmente no setor de serviços e da construção civil, no caso dos homens. As mulheres dedicam-se principalmente ao trabalho no lar e ao trabalho doméstico em outras residências. Os jovens que já trabalham, também exercem atividades com menores exigências de qualificação. Muitos destes jovens, no entanto, estão com projetos de continuar a estudar e de cursar o $3^{\circ}$ grau de ensino, enquanto o nível de escolaridade de seus pais era, com pouquíssimas exceções, o $1^{\circ}$ grau de ensino incompleto.

Não se pode concluir que os homens estejam vivenciando com maior dificuldade as contradições entre modelos hierárquicos e igualitários de família. Parece que em Antônio Carlos, as famílias ainda estão constituídas segundo padrões hierárquicos, com as mulheres trabalhando lado a lado com o marido, mas bastante dependentes de suas decisões, no que se refere ao mundo público. Estas mulheres, que já vinham de uma tradição de trabalho "fora”, na roça com os maridos, continuam acompanhando-os nas novas atividades que empreendem: são feirantes, fazem sacolões na Região Metropolitana de Florianópolis, especialmente na capital, indo também para municípios mais distantes. Os empreendimentos são, em geral, conjuntos, inclusive o de trabalharem fora, em outros tipos de atividade. Como uma das informantes ressaltou, "os ganhos são pro monte”.

As entrevistas destacam a ideologia do trabalho, presente nas representações de muitos informantes, especialmente da geração mais velha e entre as mulheres.

As mulheres dos dois municípios, mesmo trabalhando fora do lar, ainda são responsáveis pelas tarefas domésticas, ou estas ficam sob a responsabilidade das filhas.

Apesar de parecer estar havendo uma maior flexibilização na divisão sexual do trabalho, as tarefas realizadas dentro da casa pelos homens são tidas, ainda, como ajuda pela qual as mulheres devem ficar reconhecidas, definindo inclusive o bom marido e o 
bom filho.

O poder de decisão e autonomia das mulheres parece estar aumentando, com sua saída para o trabalho remunerado fora do lar, embora algumas delas ainda abdiquem desta autonomia.

Com relação à adolescência, parece que os jovens pesquisados nos dois municípios não se diferenciam muito de adolescentes de outras camadas sociais do mundo urbano. Apenas com oportunidades mais limitadas, vêem os mesmos programas de televisão, gostam de assistir a shows, ir a bailes e danceterias, namorar, sair com os amigos. Referenciam-se nas "turmas”, quase não lêem, estudam para "ser alguém na vida", pretendem trabalhar. Em suas representações, adiam os projetos de constituir família para depois de se qualificarem para o trabalho, embora entre a maioria das moças, o casamento apareça como perspectiva para o futuro.

O projeto familiar coletivo parece ter ainda primazia para as famílias das pessoas entrevistadas, especialmente no que se refere à geração dos pais. Quanto aos jovens, nota-se uma tendência mais marcada de construção de projetos em conformidade com o ideário individualista/igualitário que, na concepção de Dumont (obras citadas), caracteriza a sociedade moderna. Estes projetos, no entanto, encontram menores facilidades de realização, apesar do maior leque de oportunidades que as cidades possam oferecer (educação, informação, trabalho, etc.), em função dos problemas financeiros, da instabilidade dos empregos dos pais e dos empregos dos próprios jovens, especialmente entre os sujeitos pesquisados no município de Biguaçú. Pelo fato de disporem de poucos recursos econômicos, qualquer circunstância desfavorável, como perda de emprego, uma gravidez inesperada, pode significar a impossibilidade de realização de planos para o futuro, levando ao abandono de projetos de vida. Nestes casos, muitas vezes, com o recurso à solidariedade do grupo familiar e com a adesão aos projetos coletivos da família.

Nos movimentos dos sujeitos e famílias estudados, pode-se perceber a dinâmica social que Louis Dumont analisa através da relação englobante/englobado, em que o elemento subordinado é subsumido pelo elemento dominante, mas fica nele contido, podendo tornar-se, numa reversão de posições, o elemento englobador. Assim, pode-se perceber a coe- xistência de projetos igualitários e hierárquicos de relações entre sujeitos e entre diferentes gerações, nas famílias pesquisadas.

As análises das entrevistas e questionários realizados mostraram a grande mobilidade dos sujeitos entre os municípios da Região Metropolitana e a dependência, em relação aos serviços de saúde, de Florianópolis e também de São José, com a construção ali de um hospital público. Com relação a comércio, trabalho, estudo, existe um constante intercâmbio entre as cidades da área de conurbação, com fluxo acentuado em direção à capital à zona comercial de São José.

Pode-se perceber que esses sujeitos vivenciam as experiências de urbanização de seus espaços e modos de vida, particularmente, cada um a seu modo, adaptando-se a novas atividades, ressignificando suas estratégias de sobrevivência, suas relações e a si próprios. Cada sujeito com suas características, suas esperanças, alegrias, mágoas. Cada sujeito com sua história de vida.

\section{Referências Bibliográficas}

Da Matta, R. (1978). O ofício do Etnólogo, ou como ter "Anthropological Blues". Em E. de O. Nunes (org.), A aventura sociológica: objetividade, paixão, improviso e método na pesquisa social (pp. 23-35). Rio de Janeiro: Zahar.

Duarte, L.F.D. (1986). Da Vida Nervosa nas Classes Trabalhadoras Urbanas. Rio de Janeiro: Jorge Zahar/ CNPq.

Dumont, L. (1985). O Individualismo: uma perspectiva antropológica da ideologia modern. (Á. Cabral, Trad.). Rio de Janeiro: Rocco.

Dumont, L. (1992). Homo Hierarquicus: o sistema das castas e suas implicações. (C.A. Fonseca, Trad.) São Paulo: EDUSP/CNPq.

Figueira, S. (1985). Cultura da Psicanálise. São Paulo: Brasiliense.

Figueira, S. (1987). Uma Nova Família? Rio de Janeiro: Jorge Zahar.

Freud, S. (1969). Três ensaios sobre a teoria da sexualidade. Em Edição Standard Brasileira das 
Obras Psicológicas Completas de Sigmund Freud, vol. VII, (pp. 127-228). (P.D. Corrêa, Trad.) Rio de Janeiro: Imago. (Trabalho original publicado em 1905)

Freud, S. (1969). Identificação. Em Edição Standard Brasileira das Obras Psicológicas Completas de Sigmund Freud, vol. XVIII, (pp. 133-139). (C.M. Oiticica, Trad.) Rio de Janeiro: Imago. (Trabalho original publicado em 1921)

Freud, S. (1969). A dissolução do complexo de Édipo. Em Edição Standard Brasileira das Obras Psicológicas Completas de Sigmund Freud, vol. XIX, (pp. 217-224). (J.O.A. Abreu, Trad.) Rio de Janeiro: Imago. (Trabalho original publicado em 1924)

Freud, S. (1969). Algumas conseqüências psíquicas da distinção anatômica entre os sexos. Em Edição Standard Brasileira das Obras Psicológicas Completas de Sigmund Freud, vol. XIX, (pp. 309-320). (J.O.A. Abreu, Trad.) Rio de Janeiro: Imago. (Trabalho original publicado em 1925)

Freud, S. (1969). Sexualidade feminina. Em Edição Standard Brasileira das Obras Psicológicas Completas de Sigmund Freud, vol. XXI, (pp. 259-279). (J.O.A. Abreu, Trad.) Rio de Janeiro: Imago. (Trabalho original publicado em 1931)

Freud, S. (1969). Feminilidade. Em Edição Standard Brasileira das Obras Psicológicas Completas de Sigmund Freud, vol. XXII, (pp. 139-165). (J.L. Meurer, Trad.) Rio de Janeiro: Imago. (Trabalho original publicado em 1933)

Harvey, D. (1989). Condição Pós-Moderna: uma pesquisa sobre as origens da mudança cultural. (A.U. Sobral \& M.S. Gonçalves, Trads.) São Paulo: Edições Loyola.

Heilborn, M.L. (1992). Dois é Par: conjugalidade, gênero e identidade em contextos igualitários. Tese de Doutorado, Universidade Federal do Rio de Janeiro/Museu Nacional, Rio de Janeiro.

Lacan, J. (1979). O Seminário. Livro 11: Os quatro conceitos fundamentais da Psicanálise. Rio de Janeiro: Jorge Zahar. (Trabalho original publicado em 1933)
Lago, M.C. de S. (1996). Modos de Vida e Identidade: sujeitos no processo de urbanização da Ilha de Santa Catarina. Florianópolis: Editora da UFSC.

Lago, M.C. de S., Souza, N.O.S. \& Vieira, F.T. (1995). Mulher e Identidade: um estudo sobre gênero no processo de transformação social da Ilha de Santa Catarina (Relatório Final de Pesquisa PIBIC/CNPq). Florianópolis: UFSC.

Lago, M.C. de S., Santos, A.C.W. \& Silva, J.A. (1996). Juventude e Modos de Vida: um estudo sobre gênero entre jovens da Ilha de Santa Catarina (Relatório Final de Pesquisa PIBIC/ CNPq). Florianópolis: UFSC.

Lago, P.F. (1996). Florianópolis: A polêmica Urbana. Florianópolis: Fundação Franklin Cascaes; Palavra Comunicação.

Lyotard, J.F. (1998). A condição pós-moderna. (R.C. Barbosa, Trad.). Rio de Janeiro: José Olympio.

Marcon, M.T. de R. (2000). A Metropolização de Florianópolis: o papel do Estado. Dissertação de Mestrado defendida no programa de pós-graduação em Geociências da UFSC. Florianópolis. (xerog.)

Paquette, D. (1994). Identidade, linguagem e relações interétnicas: o caso dos brasileiros de origem alemã. (Relatório Final de Pesquisa PIBIC/ CNPq). Florianópolis: UFSC.

Romanelli, G. (1993). Famílias de Classes Populares: socialização e identidade masculina. Ribeirão Preto: USP.

Salém, T. (1989). O Casal Igualitário: princípios e impasses. Revista Brasileira de Ciências Sociais, 3(9), 24-37.

Schulze, C. (1996). Identidade Étnica, Representações Sociais e Linguagem (Relatório Final de Pesquisa CNPq). Florianópolis: UFSC.

Seyferth, G. (1974). A Colonização Alemã no Vale do Itajaí-Mirim. Porto Alegre: Movimento.

Siqueira, M.J.T. (2000). A constituição da identidade masculina: alguns pontos para discussão. Em J. Pedro, \& M. Grossi (orgs.), Masculino, Femi- 
nino, Plural (pp. 209-227). Florianópolis: Mulheres.

Velho, G. (1983). Individualismos e desmapeamento: Antropologia e Psicanálise. Em Anuário Antropológico 81. Fortaleza: Edições Universidade Federal do Ceará/Rio de Janeiro: Tempo Brasileiro.

Velho, G. (1987). Individualismo e Cultura. Rio de Janeiro: Zahar.

As autoras agradecem ao Programa de Iniciação Científica PIBIC/UFSC, pelas bolsas concedidas às alunas na realização da pesquisa ora relatada. 